\title{
Is the future a political economy? Functional analysis of three leading foresight and futures studies journals
}

\author{
Steffen Roth, ESC Rennes School of Business, France \\ Jari Kaivo-oja, University of Turku School of Economics, Finland \\ Published in Futures Vol. 81 \\ DOI: http://dx.doi.org/10.1016/j.futures.2015.10.002 \\ Corrected proof available for download here: \\ https://steffenroth.files.wordpress.com/2015/11/futures-1-s2-0-s0016328715001366-main.pdf
}

Abstract: This article tests whether the field of foresight and futures studies shows significant variable selection biases in the modelling of the future in general and the impact of function systems in particular. We performed a word frequency analysis to measure the relative importance of the political system, the economy, science, art, religion, law, sport, health, education, and the mass media to three pertinent journals in the field of futures studies and foresight. The results show that Futures, Long Range Planning, and Technological Forecasting and Social Change have different and changing preferences for the above function systems, an information which authors may find helpful in supporting decisions on where to submit. Our results also show that all journals feature a highly significant bias to the triple helix systems - the political system, the economy, and science. While the latter bias may be adequate to scientific journals, the dominant focus on the political system and the economy as well as the corresponding neglect of the other systems points at implicit presumptions about the importance of the individual systems that may not be in line with their importance to the larger society.

Highlights: This article

- Shows that present visions of futures are predominantly visions of political economies, and how to change this.

- Suggests that solutions to future political and economic key problems might also be in the so-far neglected further function systems.

- Proposes a new systematic set of key variables for consideration and inclusion in models and simulations of futures.

Keywords: Functional differentiation; function systems; key variables; modelling; social systems.

\section{Introduction. The key variables of foresight and futures studies}

Research in futures is often advised to start with the identification of key variables likely to influence these futures. Anxious "to find the factors and trends that are really important" (Godet and Roubelat 1996, 164), foresight and futures studies has therefore been most concerned with economic, political, technological, and ecological developments (Bretschneider and Gorr 1992). This focus has early been criticized, for example, as being ethnocentric (Goonatilake 1992; Sardar 1993, Sardar 2010). Claims for a more systematic consideration of social or socio-cultural factors have not been unheard of (Rubin and Kaivooja 1999; Bell 2011, Sardar 2010), and "socio-cultural developments" (van Notten et al. 2003) or "social variables" (Soyer and Hogarth 2012) are meanwhile included in a certain number of foresight and futures studies. Yet, the focus on the traditional key variables and factors 
remains strong (Slaughter 2008a, 2008b, Sardar 2010), while the question of how key variables are actually identified and weighted has still not received much scientific attention. Many accurate forecasts therefore might remain contingent on preconceived sets of variables, thus running the third-order risk of giving the right answers to the wrong questions (Godet 1986). ${ }^{1}$

The right question may wish to ask is therefore how contemporary foresight and futures research critical variables are actually selected. This question is critical not only for theorizing in foresight and futures research (Keenan et al. 2003, Öner 2010; Piirainen and Gonzalez 2015, Son 2015, Kaivo-oja 2015), but also because all tools applied in the field involve a concentration on certain factors and the neglect of others; and it appears even more critical when we assume that processes of the identification of key factors and trends might follow trends themselves. Notably such fashionable biases in the selection of supposed key factors would hence considerably jeopardise the accurateness, scope, and impact of research in foresight and futures studies.

The aim of the present article is to test the assumption that the field of foresight and futures research features significant observational and variable selections biases when it comes to the analysis and modelling of "soft systems such as national and local government, politics, international relations, demographics, economics, justice, crime, sociology, culture, media and religion" (Samet 2011, 835). To this end, we first draw on theories of social differentiation so as to unfold a map of differences that make a difference (Bateson 1972) in social sciences. Against the background of this map, we will then show that modern societies are distinguished by the distinction of autonomous function systems such as the political system, the economy, science, art, religion, law, sport, health, education, and the mass media system $^{2}$. In a next step, we will analyse the extend to which three prominent journals in the field, Futures, Long Range Planning, and Technological Forecasting and Social Change, have actually been referring to these function systems from their first issue on to March 2015. As the results display significantly skewed distributions of the attention devoted to the different function systems, which also deviate from word frequency distributions as found in a reference corpus, we finally suggest that, in the future, foresight and futures research be more concerned with its key factors and key variables selection strategies.

\section{Social differentiation. Toward a map of function systems}

This research is motivated by the impression that the future in forecast and futures research is most often about political and economic factors. This, still supposed, political-economic bias took us by surprise because we tended to conceive of futures and futures studies also as spaces for the exploration of alternatives and not only as mere extrapolations of perceived status quos. That said, this text is not simply a call for more factors and variables to be taken into account in future foresight and futures research. Rather, we understand that "because the possibilities in any given situation are far too numerous to do exhaustive searching, futures researchers generally apply various 'rules of thumb' to do the initial narrowing" (Amara 646). We hence agree with the idea that highly instructive models even of the entire world can be built using only a very small number of variables. Our only concern is that, in the overall majority of the cases, the world is naturally reduced to a very small set of economic and political variables, just as if there was nothing more natural than claiming that our future depends more on political and economic than on religious or sportive categories. In fact, the

\footnotetext{
${ }^{1}$ There are also considerable risks that political agendas are biased because of this third-order risk. In many foresight studies a key research idea is to construct future-oriented political decision-making agendas (Rikkonen et al. 2006, van Asselt et al. 2010).

${ }^{2}$ See Roth and Schütz (2015) for a detailed derivation of the above list of ten function systems.
} 
idea of a world model focused mainly on artistic factors appears amusing rather than informative. And this contrast between economic and artistic world models is exactly where the surprise and the questions come in: Why do our bellies tell us that artistic or sportive facts are not hard enough to enter or even dominate world models? What actually make us buy the idea that economic policies are more important to our future than religious education? Why is it that we single out economic and political variables and leave the rest in the social or culture container, ${ }^{3}$ thus also implying that economies or politics are neither social phenomena nor forms of culture themselves?

It is against the background of these questions that we suggest engaging in an interaction of foresight and futures studies on the one hand and social differentiation theory on the other, which is even more crucial as the, probably justified, prominence of the economic and the political system can be observed only against the background of a rather recent form of social differentiation.

Maps are models. Our basic model of social differentiation therefore starts from a blank sheet of paper that might make a good map sheet. We find that the concept of an unmarked space (Spencer Brown 1979; Luhmann 1993, 1995a) is close to this ideal of a blank sheet on which the distinctions drawn appear as differences that make a difference (Bateson 1972). This sheet of paper becomes a map (and not a cartoon) only after the first lines have been drawn. It is thus the distinctions drawn that make the map in which they exist.

In mapping social differentiation, the first distinction we need to draw is the distinction of similar and dissimilar social systems ${ }^{4}$. In a second step, we add the distinction of equal and unequal systems. The cross tabling of these two distinctions already provides systematic insights into the core concepts of fundamental works on social differentiation (Durkheim 1933; Marx 1867; Spencer 1895; Tönnies 1887). In fact, all canonical trend statements on the shifts from mechanic to organic solidarity, from association to organization, from homogeneity to heterogeneity, from natural states to forms of alienation, or from community to society, base on arguments that follow or cross the lines between dissimilarity and similarity. Dissent only occurs with regard to the second distinction (Giddens 1973, 230; Cattacin 2001, 7; 14): A Durkheimian tradition of sociology considers inequalities avoidable side effects of social evolution, i.e., of a basically positive process of increasing whereas a Marxist tradition takes inequality for the inevitable collateral damages of specialization and thus calls for a fundamental redesign of an essentially misrouted development of human history. Niklas Luhmann (1977) abstracted from both forms of value judgments and combined the two distinctions dis-/similar and in-/equal, thus developing what can be presented as one of the briefest possible mapping of historical and present forms of society (cf. Table 1):

\begin{tabular}{|c|c|c|c|}
\hline & \multicolumn{2}{|c|}{ Equal } \\
\hline & & + & - \\
\hline \multirow{2}{*}{ Similar } & + & $\begin{array}{c}\text { Segmentation } \\
\text { (Families, tribes, nations, etc.) }\end{array}$ & $\begin{array}{c}\text { Centralization } \\
\text { (Civilizations, empires, etc.) }\end{array}$ \\
\hline & - & $\begin{array}{c}\text { Functional Differentiation } \\
\text { (Economy, Science, Art, etc.) }\end{array}$ & $\begin{array}{c}\text { Stratification } \\
\text { (Castes, estates, classes, etc.) }\end{array}$ \\
\hline
\end{tabular}

Table 1: Social Differentiation (slightly modified from Roth 2014a, 442)

The fundamental units of archaic societies were similar and coequal segments such as clans, and tribes until some segments started to exert larger influence on surrounding

\footnotetext{
${ }^{3}$ This is the case whenever foresight is classically defined as "the process involved in systematically attempting to look into the longer-term future of science, technology, the economy and society" (Martin 1995, 140; emphasis added)

${ }^{4}$ In this context, social systems are sufficiently well defined as position markers of social realities (Luhmann 1995b, 12).
} 
segments than others. Although centrality is not necessarily an advantage, in many cases centralization has been the basis for social stratification, the latter of which is characterized by the distinction of neither similar nor equal strata like castes, estates, or classes. In spite of a still strong prevalence of hierarchies, a functional differentiation of both dissimilar and equal subsystems such as politics, the economy, science, art, religion, or education is said to be the dominant form of social differentiation in modern societies. Modern man naturally insists on the separation of powers, talks business, and avoids religion in small talk. Next to organization, functional differentiation is therefore considered a key principle of modern societies (Luhmann 1977; Leydesdorff 2002; Beck, Bonss, and Lau 2003; Vanderstraeten 2005; Brier 2006; Bergthaller and Schinko 2011; Jönhill 2012).

While organization is routinely taken as standpoint of observation in foresight and futures research (van Notten et al. 2003), functional differentiation is still implied rather than applied in the field. This is true insofar as, in readily zooming in on political and economical issues, most studies perform rather than challenge an assumed political and economic bias of modern societies, thus projecting it to the future. Recent culturomic research, however, suggests that it is better to exercise caution when it comes to the definition of modern societies as economized (Roth 2014b) and not as, e.g., mediatized (Castells 1996; Chomsky 1997; Hjarvard 2008; Croteau and Hoynes 2003; Mazzoleni 2008) or aestheticized (Blumler and Kavanagh 1999). And a look back at the role of religion in earlier and contemporary societies also suggests that the importance of individual function systems is subject to change. The challenge is hence to explore which directions this change might take in the future. For this to be possible, however, foresight and futures studies might first need to get wise on its own trends in the selection of supposed or actual key variables. The subsequent sections of this article are therefore devoted to an inquiry in supposed or actually existing biases to particular function systems featured by three prominent journals of foresight and futures studies.

\section{Hypotheses. Soft systems, hard biases}

Though often observed, the circumstance that particular function systems are considered more relevant than others is not understood without ambiguity. In the light of the function systems' fundamental incommensurability (Vanderstraeten, 2005; Jönhill, 2012) and autonomy (Tsivacou, 2005; Valentinov, 2012), there is no way of arguing that the economy or the political system is more important than health, sport, art, or religion, per se. On the other hand, there is plenty of (supposed) evidence of such imbalances, with the most popular ideas being that either the economy or the political system is the most dominant function system (Risse, 2003; Wallerstein, 2003; Foucault, 2008; Urry, 2010; Lash, 2007). This contradiction can be resolved by stating that it is not despite, but precisely because of their incommensurability that function systems can be ranked at all because if the function systems were essentially unequal, they would already be ranked and, therefore, could no longer be ranked. The basic assumption of the functional equivalent and mutually exclusive nature of function systems hence makes an excellent fundament for a null hypothesis. Representing coequal nominal data, function systems can be assumed equally relevant to the three foresight and futures studies journals. The null hypothesis is therefore as follows:

(H0) Function systems relevancies exhibit a uniform distribution in the three foresight and futures studies journals.

Our initial educated guess, however, was that some function systems are more important than others in foresight and futures studies. Thus, our alternative hypothesis reads as follows: 
(H1) Function systems relevancies exhibit an unequal distribution in (H1.1) and in between the three foresight and futures studies journals (H1.2).

As we may also be interested in learning more about trends in function systems preferences in foresight and futures research, we also suggest testing the following hypothesis:

(H2) The distributions of function systems relevancies are subject to change over time in the three foresight and futures studies journals.

To finally analyse if the function system preferences displayed in foresight and futures research is in line with the importance that the individual function system have to the larger society, we also suggest testing the subsequent hypothesis:

(H3) The distributions of function system relevancies exhibited by the three journals are different from the function system relevancies of larger text corpora.

\section{Counting functions. Operationalising a systematic function systems lens on Futures, Long Range Planning, and Technological Forecasting and Social Change}

The key assumption proposed in this article is that foresight and futures studies more or less consciously takes particular function systems for more important than others. To detect and analyse the importance particular function systems have to the field, we performed a non-case sensitive word frequency analysis of the full text archives of three leading foresight and futures research journals. We opted for Futures, Long Range Planning, and Technological Forecasting and Social Change because of their seniority, impact, and accessibility through the same platform and search interface (ScienceDirect).

The search terms presented in Table 2 had been extracted from the English Google Million corpus $^{5}$, the ten separate fractions of which we had merged and transformed to a ranked word frequency list of books published from 1800-2000. We had then scanned the 2000 most frequent words of this list for terms that unambiguously refer to one of the presumably ten function systems (Roth 2014b): the political system, the economy, science, art, religion, law, sport, health, education, and the mass media system. Because there had been no sportive term to appear in the Top2000, we extended our search to rank 6673 in this particular case.

The importance of the function systems was hence defined in terms of the frequency of their occurrence in one of the world most comprehensive corpora. Word frequency is considered "the simplest and most impartial gauge of word importance" (Kloumann et al., 2012:1) or the importance of objects, ideas, and persons (Ophir, 2010; Bohannon, 2011), respectively. Accordingly, we counted the word frequencies of all search terms as listed in Table 2 in Futures, Long Range Planning, and Technological Forecasting and Social Change.

\footnotetext{
${ }^{5}$ Since 2004, the Google Books project has digitalized some 15 million of the estimated 115 million books ever published. A Harvard research team (Michel et al., 2011) performed considerable quality checks and compiled a representative corpus of more than five million books or 500 billion words covering seven language areas and a time span of 600 years. A more condensed version of this huge corpus is the also representative Google One Million (2009), available at https://books.google.com/ngrams/datasets, which represent the only corpus that proves manageable with end-user hardware.

The development of this enormous data soon raised hopes of a golden age of digital humanities (Johnson, 2010), which would open up new types of historical knowledge (Ophir, 2010), as it has already given birth to the discipline of culturomics as "the application of high-throughput data collection and analysis to the study of human culture" (Michel et al., 2011:181). The access to the Google Books corpus is facilitated by the Google Ngram Viewer - an open-access interface that allows for trending (Manovich, 2012) in terms of the production of customized time-series plots for entered search terms.
} 


\begin{tabular}{|c|c|c|c|c|c|c|}
\hline \multirow{2}{*}{$\begin{array}{l}\text { SYSTEM } \\
\text { Political }\end{array}$} & \multicolumn{5}{|c|}{$\begin{array}{c}\text { SEARCH TERMS } \\
\text { Selected per word count in the Google One Million corpus (2009) }\end{array}$} & \multirow{2}{*}{$\begin{array}{c}\% \\
\text { SYSTEM } \\
20.6\end{array}$} \\
\hline & $\begin{array}{c}\text { States }^{6} \\
58755598\end{array}$ & $\begin{array}{c}\text { war } \\
31149812 \\
\end{array}$ & $\begin{array}{l}\text { government } \\
29645785 \\
\end{array}$ & $\begin{array}{c}\text { political } \\
22877969\end{array}$ & $\begin{array}{c}\text { force } \\
22024598\end{array}$ & \\
\hline Economy & $\begin{array}{l}\text { business } \\
21520868\end{array}$ & $\begin{array}{c}\text { money } \\
21509015\end{array}$ & $\begin{array}{c}\text { trade } \\
14334296\end{array}$ & $\begin{array}{l}\text { economic } \\
13005167\end{array}$ & $\begin{array}{c}\text { paid } \\
12266819\end{array}$ & 10.3 \\
\hline Science & $\begin{array}{c}\text { truth } \\
17377316 \\
\end{array}$ & $\begin{array}{c}\text { idea } \\
16586273\end{array}$ & $\begin{array}{c}\text { method } \\
15815508\end{array}$ & $\begin{array}{c}\text { theory } \\
13378152\end{array}$ & $\begin{array}{c}\text { science } \\
9993222\end{array}$ & 9.1 \\
\hline Art & $\begin{array}{c}\text { art } \\
15034765\end{array}$ & $\begin{array}{c}\text { poetry } \\
10723708\end{array}$ & $\begin{array}{c}\text { style } \\
8114211\end{array}$ & $\begin{array}{c}\text { music } \\
8012343\end{array}$ & $\begin{array}{c}\text { design } \\
7999303\end{array}$ & 6.2 \\
\hline Religion & $\begin{array}{c}\text { God } \\
47147531\end{array}$ & $\begin{array}{c}\text { Church } \\
18579571\end{array}$ & $\begin{array}{c}\text { Christ } \\
14688833\end{array}$ & $\begin{array}{l}\text { religious } \\
13705354\end{array}$ & $\begin{array}{c}\text { religion } \\
12863620\end{array}$ & 13.4 \\
\hline Law & $\begin{array}{c}\text { law } \\
70740344\end{array}$ & $\begin{array}{c}\text { property } \\
16219929\end{array}$ & $\begin{array}{c}\text { legal } \\
14566194\end{array}$ & $\begin{array}{c}\text { duty } \\
12149134\end{array}$ & $\begin{array}{c}\text { Court } \\
11935612\end{array}$ & 15.7 \\
\hline Health & $\begin{array}{c}\text { care }^{7} \\
16059483\end{array}$ & $\begin{array}{l}\text { treatment }^{8} \\
12398779\end{array}$ & $\begin{array}{c}\text { health } \\
11130569\end{array}$ & $\begin{array}{l}\text { patients } \\
8311566\end{array}$ & $\begin{array}{l}\text { medical } \\
5548925\end{array}$ & 6.7 \\
\hline Sport & & & $\begin{array}{c}\text { sport }^{9} \\
1388520\end{array}$ & & & 0.1 \\
\hline Education & $\begin{array}{c}\text { school } \\
23315013\end{array}$ & $\begin{array}{c}\text { students } \\
18735874\end{array}$ & $\begin{array}{c}\text { College } \\
15944650\end{array}$ & $\begin{array}{l}\text { education } \\
14936010\end{array}$ & $\begin{array}{l}\text { learning } \\
7636407\end{array}$ & 10.1 \\
\hline Media & $\begin{array}{c}\text { book } \\
20664695\end{array}$ & $\begin{array}{l}\text { literature } \\
16620864\end{array}$ & $\begin{array}{l}\text { published } \\
12058050\end{array}$ & $\begin{array}{c}\text { library } \\
7309954\end{array}$ & $\begin{array}{c}\text { Journal } \\
6543884\end{array}$ & 7.9 \\
\hline
\end{tabular}

Table 2: List of search terms per function system including word count in the Google One Million corpus (own table)

In a next step, we repeated the count for all articles published before 2000 and after 1999, respectively. We then computed and compared the ratios of function system references for each journal, for each period within each journal, across the journals, and for each period across the journals. We also compared these ratios to the ratio of function system references as displayed in the Google One Million corpus 2009. In all cases we used the chi-square test to identify significant differences between the compared samples; because of the poor performance of sport in the Google corpus we did not take sport into account in the definition

\footnotetext{
${ }^{6}$ The most popular political term in the Google One Million corpus is power (ranked 117 among the most frequent words with a word count of 93274952). However, power may also refer to, e.g., electric power or steam power, in which cases the word clearly does not have a political meaning. We hence excluded the political system's most powerful term. The term States is unambiguously political only with the initial capital letter. Unlike Google ngram queries, ScienceDirect queries run non-case sensitive. There may hence be rare cases in which the political system benefitted from expressions such as state-of-the-art, which we consider an only small compensation for the loss of its most powerful term.

${ }^{7}$ Care refers not only to medical care, but also to help in cases of psychological or social problems. Our claim that care refers to the health system is in line with recent claims for a broader concept of health and the corresponding health or care system (Roth and Schütz 2015). Moreover, the health system accounts for only $2.5 \%$ of the function system related terms among the 2000 most frequent words in the Google One Million, thus being the second-least important function system in the corpus. We therefore opted for a more generous interpretation of health system reference (cf. also the next footnote).

${ }^{8}$ The health-reference of the term treatment comes with some ambiguities. Yet, even rather technology oriented word uses such as in the case of water treatment often have a health related connotation.

${ }^{9}$ Neither sport nor any sportive term is included in the 2000 most frequent words in the Google One Million corpus. The first sportive term to appear in the corpus is sport (ranked 6673 with a word count of 1388520).
} 
of the expected frequencies of the other function systems. To allow for comparisons between the journals, we weighted the individual word counts against the journals' page counts. ${ }^{10}$

\section{Results. An absolute majority for the economy, the political system, and science}

The ten function systems exhibit significantly unequal distribution both within and across the examined journals Futures (FUT), Long Range Planning (LRP), and Technological Forecasting and Social Change (TFSC) (cf. Tab. 3): The economy, the political system, and science clearly are the most dominant systems again both within and across all systems. The dominance of the economy is most pronounced in LRP and least pronounced in FUT. Conversely, FUT exhibits the strongest focus on the political system, while the system is comparably least attractive to LRP. TFSC displays the highest value for science, closely followed by FUT. With 53.6\% (FUT), 53.1\% (LRP), 52.2\% (TFSC), and 53.0\% for all journals, the economy, the political system, and science hold the absolute majority out of the ten function systems. The mass media system and health are also over-represented, however, not in all journals: In the case of FUT, the mass media system does not deviate significantly from the expected frequency (Tab. 4, annex). The results for education are also of comparably low significance in the cases of FUT and TFSC (Tabs. 4 and 6, annex). All remaining functions systems, however, are significantly underrepresented in all journals, which is particularly true for religion, whose share of all function system references ranges between $0.8 \%$ in LRP and $3.2 \%$ in FUT.

\begin{tabular}{|c|c|c|c|c|c|c|c|c|c|c|c|c|c|}
\hline FS & FUT & -1999 & $2000-$ & LRP & -1999 & $2000-$ & TFSC & -1999 & 2000- & ALL & -1999 & $2000-$ & Google \\
\hline POL & 20.2 & 20.5 & 19.6 & 16.6 & 17.1 & 13.7 & 18.2 & 19.3 & 17 & 18.1 & 18.6 & 17.1 & 20.5 \\
\hline ECO & 15.9 & 16.5 & 14.8 & 21 & 21.2 & 19.3 & 16.1 & 15.5 & 16.7 & 18.2 & 18.7 & 16.7 & 10.3 \\
\hline SCI & 17.5 & 17.1 & 18.1 & 15.5 & 15.4 & 16.3 & 17.9 & 18 & 17.8 & 16.7 & 16.4 & 17.5 & 9.1 \\
\hline ART & 8 & 7.8 & 8.2 & 8.7 & 8.7 & 8.7 & 7.5 & 7.1 & 7.8 & 8.2 & 8.1 & 8.2 & 6.2 \\
\hline REL & 3.2 & 3.1 & 3.4 & 0.8 & 0.7 & 1 & 1.3 & 1.8 & 0.9 & 1.7 & 1.7 & 1.9 & 13.4 \\
\hline LAW & 5.7 & 5.1 & 6.8 & 4.6 & 4.4 & 5.5 & 6.3 & 6 & 6.6 & 5.3 & 4.9 & 6.3 & 15.7 \\
\hline HEA & 6.1 & 5.7 & 6.9 & 4.8 & 4.8 & 4.8 & 6.2 & 6.2 & 6.2 & 5.6 & 5.4 & 6.1 & 6.7 \\
\hline SPO & 0.4 & 0.3 & 0.4 & 0.3 & 0.2 & 0.5 & 0.3 & 0.2 & 0.4 & 0.3 & 0.3 & 0.4 & 0.2 \\
\hline EDU & 11.9 & 11.6 & 12.4 & 13 & 12.7 & 14.7 & 12.2 & 11.4 & 13 & 12.4 & 12.1 & 13.2 & 10.1 \\
\hline MED & 11.2 & 12.2 & 9.4 & 14.8 & 14.7 & 15.5 & 14.1 & 14.5 & 13.7 & 13.4 & 13.8 & 12.5 & 7.9 \\
\hline TOTAL & 100.1 & 99.9 & 100 & 100.1 & 99.9 & 100 & 100.1 & 100 & 100.1 & 99.9 & 100 & 99.9 & 100.1 \\
\hline
\end{tabular}

Table 3: Word frequency ratios of the function systems in the journals Futures, Long Range Planning, and Technological Forecasting and Social Change (own table).

The observed frequencies also differ significantly from the expected when the latter are not assumed to be equally distributed, but rather derived from the distribution of function system references in one of the World's most comprehensive representative English language corpora. In that case, the mean observed performance of all function systems across all journals is still significantly different form the expected performance (Tab. 7, annex). Yet, in looking at the individual journals we find that FUT's attitude to the political system and FUT's and TFSC's attitude to health are in line with the two systems' importance in the literature of the last two hundred years (Tabs. 4 and 6, annex).

In looking at functional trends across the journals (Tab. 7, annex), we find that the political system and the economy are considered significantly less important since 2000, as is the mass media system. The most significant increase of interest we found in the case of the legal system. Also, education and health seem to become considerably more important.

\footnotetext{
${ }^{10}$ We counted 38627 pages for Futures (with 22798 pages before the year 2000), 31001 pages for Long Range Planning (21473 before 2000), and 45998 for Technological Forecasting and Social Change (with 23418 before 2000). The page counts are estimates only insofar as smaller issues with Roman numerals or starting page number variations between 1 and 3 have not been addressed. The above figures should nonetheless represent good approximations to the actual page counts.
} 
As to the individual journals, these follow the following trends: Since 2000, FUT is obviously increasingly interested in in legal and health issues and significantly less interested in the mass media system and the economy (Tab. 4, annex). LRP's interest in the political system and to some extend also in the economy is declining, while the legal system and education are getting more attention (Tab. 5, annex). TFSC features the strongest trend to less interest in the political system and the economy, yet, the most striking decline we observe in the case of religion. Again, education seems to be the most notable beneficiary of the journal's attention (Tab. 6, annex).

The data also allows for a certain typification of the examined journals: As compared to the other journals, FUT is characterized by a significantly stronger interest in the political system and the least pronounced neglect of religion. Also, FUT is least interested in the economy and the mass media system (Tab. 4, annex). Among all journals, RLP is least interested in religion and the political system, and most interested in the economy and the mass media system (Tab. 5 , annex). TFSC is again most disinterested in the economy and religion and most inclined to legal and scientific issues. Overall, TFSC's profile comes closest to what we could describe as the field's mainstream.

The above profiling, however, does not cover the fact that common patterns can also be observed across all examined journals. In this sense, a pronounced predominance of interest in economic, political, and scientific issues is typical for all journals, as is a considerable neglect of art, health, the legal system, and, most notably, religion.

\section{Discussion. The future as scientific observation of political economies?}

The most obvious finding of our analysis is that the function systems relevancies exhibit a significantly unequal distribution in the three foresight and futures studies journals. This finding is true for the total amount of function systems references both across and within all journals. The results therefore support the hypothesis that the different functions systems are differently important to the investigated journals, which is in line with the hypotheses H1.1 and H1.2. The evidence for H1.2, however, is less pronounced insofar as, despite still significant differences between the journals, we can also observe a certain convergence of Futures, Long Range Planning, and Technological Forecasting and Social Change. This is most obvious with regard to the fact that the triple-helix (Leydesdorff and Etzkowitz 1996, Santonen et al. 2014) systems, i.e., the political system, the economy, and science, hold absolute majorities in all three journals, with even the concrete percentages displaying only small variance (FUT: 53.6\%, LRP: 53.1\%, TFSC: 52.2\%; cf. Figure 1). 


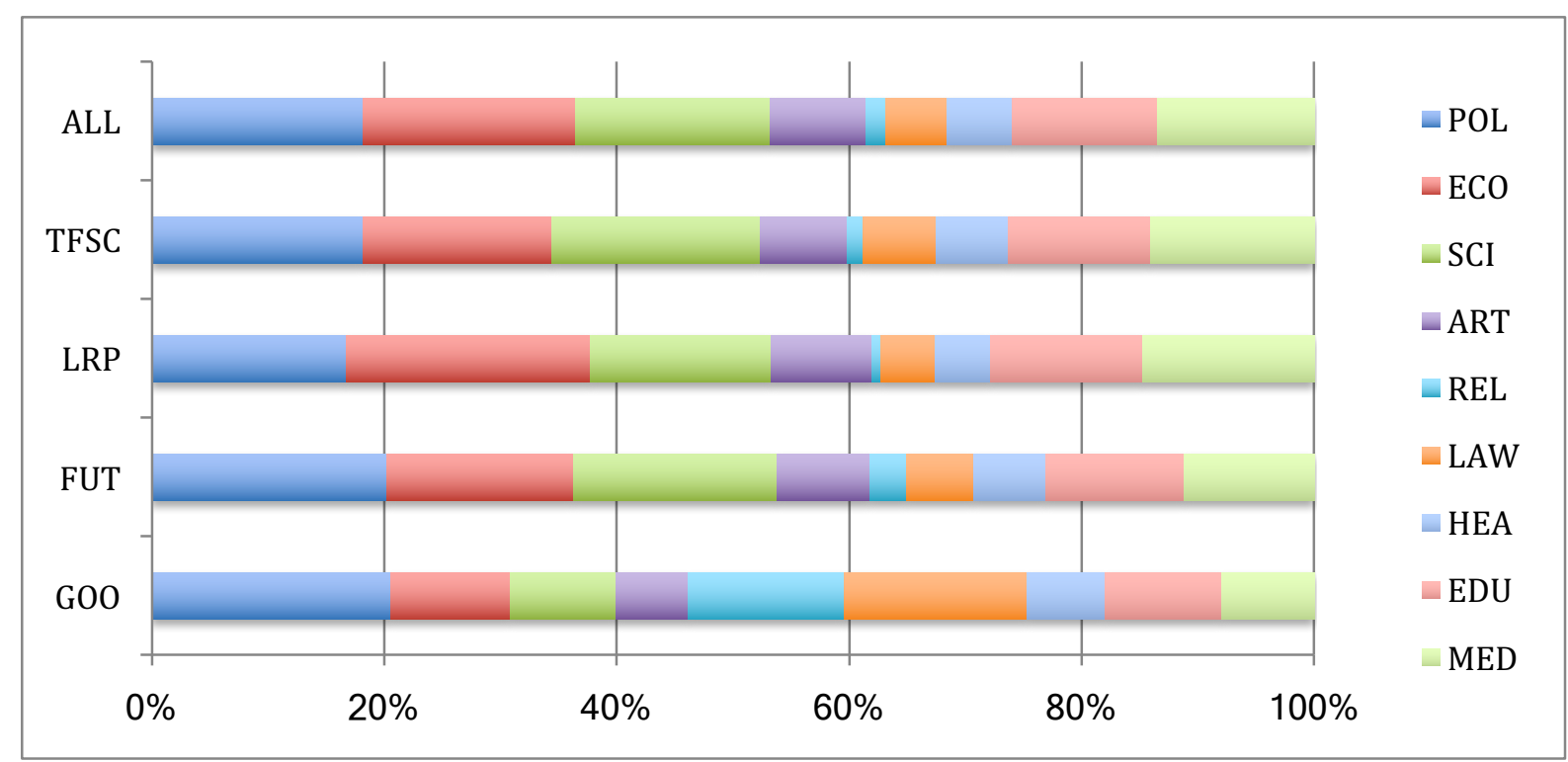

Figure 1: Word frequency ratios of the function systems in the journals Futures, Long Range Planning, and Technological Forecasting and Social Change as well as across all journals and in the Google Books corpus (own figure).

In this sense, we may be inclined to assume that a typical foresight and futures studies journal is strongly biased to the three systems, thus performing a metonymical hustle (Mermet 2009) around political, economic, and scientific concepts, which is a claim that may well be tested by a future analysis of the function system preferences of all journals in the field.

Again in line with hypothesis $\mathrm{H} 2$, the results also suggest that function system relevancies are subject to change, a finding that is, however, more evident from a cross-journal than from an in-journal perspective. In looking across the journals, for the two test-periods foundation1999 and 2000-2015 we indeed find significant changes in the frequencies of 8 out of 9 function systems. Interestingly, the increase in interest in religion is the least significant among the significant changes, a finding that challenges the idea that religion has become more important after 911 . Within the journals, the observed changes are smaller than changes across the field, where the major trend seems to be a certain decrease of interest in the political system and the economy. Still, even with now only $51.6 \%$ for the period $2000-2015$ (as compared to $53.8 \%$ for the reference period), the triple helix systems remain clearly overrepresented. This claim also proves true if we compare the performance of the function systems not against the null hypothesis, but against the idea that the function system biases displayed in foresight and futures research might be in line with prevailing biases in the overall society (hypothesis H3). In fact, the analysis of the Google book corpus, one of the world's largest English language text corpora, would suggest a share of only $40.0 \%$ for the triple helix systems, which are, hence, indeed overrepresented both within and across the journals. This overrepresentation comes at the cost of a neglect of the other function systems and is most dramatic in the case of religion, which accounts for only $1.7 \%$ of all function systems references as compared to an expected share of $13.4 \%$. Even if this enormous difference might be attributed to the much larger time frame of our Google book analysis, against the background of which religion benefits from its formerly privileged status in the $19^{\text {th }}$ century, this still to be tested argument does not explain the still on-going neglect of religion after 911. In fact, we may have expected the increasingly observed importance of religion in larger parts of the world and in the Western mass media to be reflected in the foresight and futures studies corners of the mass media system, too. Moreover, as much as we understand that science is overrepresented in scientific publications, so too do we wonder why scientific publications feature a considerable under-representation of the mass media system 
even against the background of the fact that our mass media search terms (cf. Table 2) belong to the tools of the trade in scientific publishing. In a similar way, we may wonder why science is third to both the political system and the economy in scientific observations of futures. In general, we may wish to engage in further research to explain and, when indicated, change this strong political-economic bias in foresight and futures studies, which is maybe particularly unexpected in a journal called Technological Forecasting and Social Change.

\section{Conclusion. Outlook to less mundane world models}

Our research showed that Futures, Long Range Planning, and Technological Forecasting and Social Change have considerably different preferences for the function systems of society and, hence, the corresponding topics. Authors may find this typification helpful in supporting decisions on where to submit.

With regard to the overall field of futures studies, our research adds a new dimension to the discussions on the foundations of foresight and futures studies (Masini 1993, Masini \& Gillwald, 1990; Inayatullah 1990; Malaska 1995; Keenan et al. 2003; Slaughter 2005, Lombardo 2008, Loveridge 2009; Miles 2010; Martin 2010; Marien 2010, Cummings \& Daellenbach 2009; Sardar 2010; Kuosa 2012, Son 2015). Recently, Hyeonju Son (2015) presented a historical analysis of Western futures studies. He identified three phase periodization: (1) the scientific inquiry and rationalization of the futures (1945-1960s), (2) the global institution and industrialization of the futures (1970s-1980s) and (3) the neoliberal view and fragmentation of the futures (the 1990s-the present). The function systemic lens presented in this article both fundamentally challenges this neoliberal gaze and establishes a basis for the observation of alternative futures. Son (2015) also suggested that the above trends result from a marginalization of non-western thinkers and writers, which had already been identified in the controversial article of Sardar (1993). Not least because of the rise of BRICS and developing countries, there is hence a vital need for studying and exploring alternative futures from diverse perspectives and through both multicultural and multifunctional lenses. ${ }^{11}$ Our analysis furthermore links to Sardar (2010), who has proposed four laws of futures studies which can be helpful in the new orientation of futures studies. ${ }^{12}$ This is true because (1) our study analyzed how wicked problems have actually been approached in three scientific journals of futures studies and foresight research; (2) our study shed new light how the MUD principle works in the fields of futures studies and foresight; (3) our study included hypotheses, which are deeply rooted in a skeptical paradigm; and, finally, (4) our empirical analyses provided value added analyses of fundamental key biases of futures studies and key journals of the field. These results (5) are useful for current thinking and decision-making (Sardar's futurelessness principle). In analysing the relative importance of the political system, the economy, science, art, religion, law, sport, health, education, and the mass media to three major foresight and futures studies journals, our research indeed suggests that a considerable bias to the triple helix systems and a corresponding neglect of the remaining function systems belongs to the above foundations of the field. In fact, our results clearly showed that all three journals have in common this strong bias to the political system,

\footnotetext{
${ }^{11}$ One outcome of such a multifunctional approach to present and future societies might be in the insight that the evoked clash of Christian and Muslim cultures is not so much about religious differences, but rather about a different importance of religion. Western social sciences in general and foresight and future studies in particular are therefore well-advised to critically reflect upon their own preferences for the political system and the economy and their neglect of the religious systems. This also implies that a culture's strong(er) interest in religion can no longer be prejudged as a pre-modern or traditional trait, but must be considered as a preference which is as justified and contingent as is the Western political-economic gaze.

12 These four Laws were: (1) Futures studies are wicked; (2) Futures studies follow the MUD principle, with MUD referring to Mutually Assured Diversity; (3) Futures studies are to remain skeptical; (4) Paradoxically, futures studies are futureless (Sardar 2010).
} 
the economy, and science. While the latter of the three biases may be adequate to scientific journals, the dominant focus on the political system and the economy points at implicit presumptions about the relative importance of all of the above function systems. Future investigations in futures may therefore wonder as to whether inquiries in these futures should remain extrapolations of the prevailing political-economic gaze or should also take so-far neglected function systems into account. In fact, the question is whether and how researcher in foresight and futures studies can be sure that futures depend more on mundane variables such as election victories, gross national products, and patents than on songs, prayers, or soccer scores. And this question remains even if we went on assuming that political and economic problems are simply more important and urgent than others, and even if we understand that "the origins of futures studies lie in a crisis (...) related to environmental politics and economics of growth" (Sardar 1993, 180f), just because it could still be that the solutions to these most urgent political and economic problems are in the other function systems.

In this sense, the aim of this article has also been to suggest a new set of key variables for selective consideration and inclusion in models and simulations of futures; and the present interaction of comparatively recent developments in social differentiation theory and established forecasting and futures research preferences indeed allows for the exploration of new horizons of foresight and futures research questions:

- Which alternative futures emerge through the lens of functional differentiation? Which function systems will be more or less important in the future?

- Secularization, politicization, economization, or mediatization of the society? Which trends are in line with present and future trends in futures research and next societies?

- How can key variables of functional differentiation be included in core models and methodologies of futures research?

- Which forms of social scanning allow for the analysis of large-scale trends in functional differentiation? Which forecasting support system may be capable of integrating information from such a broader scope of function systemic backgrounds?

- (How) Can the language of functional differentiation be used to challenge the feared fragmentation or disintegration of futures research?

- Do future studies of different function systems require different methodologies?

In approaching answers to these and further questions, foresight and futures research may also contribute to a reformulation of the growing interest in alternative futures as expressed in discussions on happiness or degrowth, in the context of which the key is maybe not in the streetlight (Godet 1986, 138, Kaivo-oja et al. 2014) of a political movement for a degrowing economy, but rather in a growing interest in other exciting function systems such as art, health, law, sport, and religion.

\section{References}

Amara, Roy. 1991. "Views on futures research methodology." Futures 23 (6):645-9.

Bateson, Gregory. 1972. Steps to an ecology of mind: Collected essays in anthropology, psychiatry, evolution, and epistemology. Chicago: University of Chicago Press.

Beck, Ulrich, Wolfgang Bonss, and Christoph Lau. 2003. "The Theory of Reflexive Modernization." Theory, Culture \& Society 20 (2):1-33. doi: $10.1177 / 0263276403020002001$.

Bell, Wendell. 2011. Foundations of Futures Studies: Human Science for a New Era: Values, Objectivity, and the Good Society. Transaction Publishers. New Brunswick (U.S.A.) and London (U.K.).

Bergthaller, Hannes, and Carsten Schinko. 2011. "Introduction: From National Cultures to the Semantics of Modern Society." In Addressing Modernity. Social Systems Theory and 
U.S. Cultures, edited by Hannes Bergthaller and Carsten Schinko, 5-34. Amsterdam and New York: Edition Rodopi.

Blumler, Jay G., and Dennis Kavanagh. 1999. "The Third Age of Political Communication: Influences and Features." Political Communication 16 (3):209-30. doi: 10.1080/105846099198596.

Bretschneider, Stuart, and Wilpen Gorr. 1992. "Economic, organizational, and political influences on biases in forecasting state sales tax receipts." International Journal of Forecasting 7 (4):457-66. doi: http://dx.doi.org/10.1016/0169-2070(92)90029-9.

Brier, Søren. 2006. "Construction of knowledge in the mass media. Systemic problems in the post-modern power - struggle between the symbolic generalized media in the Agora: the Lomborg case of environmental science and politics." Systems Research and Behavioral Science 23 (5):667-84. doi: 10.1002/sres.793.

Castells, Manuel 1996. Rise of The Network Society. Cambridge: Blackwell Publishers.

Cattacin, Sandro. 2001. "Réciprocité et échange." Revue internationale de l'économie sociale 80 (279):71-82.

Chomsky, Noam 1997. Media Control. The Spectacular Achievements of Propaganda. New York: Seven Stories Press.

Croteau, David, and William Hoynes. 2003. Media Society: Industries, Images and Audiences. Thousand Oaks: Sage.

Cummings, Stephen and Urs Daellenbach. 2009. "A guide to the future of strategy? The history of Long Range Planning", Long Range Planning 42(2): 234-263.

Durkheim, Emile. 1933. "The division of labor." Trans. G. Simpson. New York: Macmillan.

Giddens, Anthony. 1973. Capitalism and modern social theory: An analysis of the writings of Marx, Durkheim and Max Weber. Cambridge University Press. Cambridge.

Godet, Michel. 1986. "Introduction to 'la prospective': Seven key ideas and one scenario method." Futures 18 (2):134-57.

Godet, Michel, and Fabrice Roubelat. 1996. "Creating the future: the use and misuse of scenarios." Long Range Planning 29 (2):164-71.

Goonatilake, Susantha. 1992. "Reconceptualizing the cultural dynamics of the future." Futures 24 (10):977-86.

Hjarvard, Stig. 2008. "The Mediatization of Society. A Theory of the Media as Agents of Social and Cultural Change." Nordicom review 29 (2):105-34.

Inayatullah, Sohail. 1990. "Deconstructing and Reconstructing the Future: Predictive, Cultural and Critical Epistemologies," Futures, Vol. 22(2):115-141.

Jönhill, Jan Inge. 2012. "Inclusion and Exclusion-A Guiding Distinction to the Understanding of Issues of Cultural Background." Systems Research and Behavioral Science 29 (4):387-401.

Kaivo-oja, Jari, Vehmas, Jarmo \& Luukkanen, Jyrki 2014. "A note: De-Growth debate and new scientific analysis of economic growth." Journal of Environmental Protection. Vol. 5, No. 15.

Kaivo-oja, Jari (2015) "Towards better participatory foresight processes - linking participatory foresight research to the methodological machinery of qualitative research and phenomenology". Manuscript. Finland Futures Research Centre, Turku School of Economics, University of Turku.

Keenan, Michael., Loveridge, Denis, Miles, Ian \& Kaivo-oja, Jari (2003) Handbook of Knowledge Society Foresight. Prepared by PREST and FFRC for European Foundation for the Improvement of Living and Working Conditions. European Foundation. Dublin.

Kuosa, Tuomo 2012. The Evolution of Strategic Foresight. Navigating Public Policy-making. Ashgate Pub \& Gower. Surrey, UK. 
Leydesdorff, Loet 2002. "The communication turn in the theory of social systems." Systems Research and Behavioral Science 19 (2):129-36. doi: 10.1002/sres.453.

Leydesdorff, Loet, and Henry Etzkowitz. 1996. "Emergence of a Triple Helix of universityindustry-government relations." Science and public policy 23 (5):279-86.

Lombardo, Thomas 2008. Contemporary Futurist Thought: Science Fiction, Future Studies, and Theories and Visions of the Future in the Last Century. Author House. Bloomington, Indiana (U.S.A.).

Loveridge, Denis 2009. Foresight. The Art and Science of Anticipating the Future. Routledge. New York.

Luhmann, Niklas. 1977. "Differentiation of Society." The Canadian Journal of Sociology / Cahiers canadiens de sociologie 2 (1):29-53. doi: 10.2307/3340510.

1993. "Deconstruction as Second-Order Observing." New Literary History 24 (4):763-82.

1995a. "The Paradoxy of Observing Systems." Cultural Critique 31 (Fall):37-55.

1995b. Social Systems. Stanford: Standford University Press.

Malaska, Pentti 1995. "The futures field of research." Futures Research Quarterly 11(1): 7990.

Martin, Ben R. 1995. "Foresight in science and technology." Technology Analysis \& Strategic Management 7 (2):139-68.

Martin, Ben R. (2010. "The origins of the concept of 'Foresight' in science and technology: An insider's perspective." Technological Forecasting and Social Change, 77, s. 1438-1447.

Masini, Eleonora. 1993. Why Futures Studies?. London, UK: Grey Seal Books.

Masini, Elenora and Katrin Gillwald. 1990. "On future studies and their societal context with particular focus on West Germany." Technological Forecasting and Social Change 38: 187-199.

Marien, Michael. (2010) "Futures-thinking and identity: Why "Futures Studies" is not a field, discipline, or discourse: a response to Ziauddin Sardar's 'the namesake'." Futures 42(3): 190-194.

Miles, Ian. 2010. The development of technology foresight: A review. Technological Forecasting and Social Change, 77(9), s. 1448-1456.

Marx, Karl. 1867. Capital, Critique of Political Economy. Volume I. Harmondsworth: Penguin.

Mazzoleni, Gianpietro 2008. "Mediatization of society." In The International Encyclopedia of Communication, edited by W. Donsbach. Malden: Blackwell Publishing.

Mermet, Laurent. 2009. "Extending the perimeter of reflexive debate on futures research: An open framework." $\quad$ Futures $41 \quad$ (2):105-15. doi: http://dx.doi.org/10.1016/j.futures.2008.07.044.

Öner, M Atilla. 2010. "On theory building in Foresight and Futures Studies: A discussion note." Futures 42 (9):1019-30.

Piirainen, Kalle A., and Rafael A. Gonzalez. 2015. "Theory of and within foresight — "What does a theory of foresight even mean?"." Technological Forecasting and Social Change doi: 10.1016/j.techfore.2015.03.003. doi: http://dx.doi.org/10.1016/j.techfore.2015.03.003.

Rikkonen, Pasi, Aakkula, Jyrki \& Kaivo-oja, Jari. 2006. "How can future changes in Finnish agriculture and agricultural policy be faced : Defining strategic agendas on the basis of a Delphi study." European Planning Studies 14(2):147-167.

Roth, Steffen. 2014a. "Booties, Bounties, Business Models. A map to the next red oceans ". International Journal of Entrepreneurship and Small Business 22 (4):439-48. 
2014b. "Fashionable functions. A Google ngram view of trends in functional differentiation (1800-2000)." International Journal of Technology and Human Interaction 10 (3):88-102.

Roth, Steffen, and Anton Schütz. 2015. "Ten Systems: Toward a Canon of Function Systems." Cybernetics and Human Knowing: forthcoming.

Rubin, Anita, and Jari Kaivo-oja. 1999. "Towards a futures - oriented sociology." International Review of Sociology 9 (3):349-71.

Samet, Robert H. 2011. "Exploring the future with complexity science: the emerging models." Futures 43 (8):831-9.

Santonen, Teemu, Kaivo-oja, Jari \& Suomala, Jyrki. 2014. "The next steps in developing the Triple Helix Model: A brief introduction to national open innovation system (NOIS) paradigm." Journal of Systemics, Cybernetics, and Informatics, 12(7):74-82.

Sardar, Ziauddin. 1993. "Colonizing the future: the 'other' dimension of futures studies." Futures 25 (2):179-87. doi: http://dx.doi.org/10.1016/0016-3287(93)90163-N.

Sardar, Ziauddin, 2010. "The Nameshake Futures; futures studies; futurology; futuristic; foresight - What is a name?" Futures 42: 177-184.

Slaughter, Richard 2005. The Knowledge Base of Futures studies. Futures Study Centre/DDM Media.

Slaughter, Richard A. 2008a. "Integral futures methodologies." Futures 40 (2):103-8.

. 2008b. "What difference does 'integral'make?". Futures 40 (2):120-37.

Son, Hyeonju. 2015. "The history of Western futures studies: An exploration of the intellectual traditions and three-phase periodization." Futures 66: 120-137.

Soyer, Emre, and Robin M. Hogarth. 2012. "The illusion of predictability: How regression statistics mislead experts." International Journal of Forecasting 28 (3):695-711. doi: http://dx.doi.org/10.1016/j.ijforecast.2012.02.002.

Spencer Brown, George. 1979. Laws of form. New York: E. P. Dutton.

Spencer, Herbert. 1895. The principles of sociology. Vol. 1. New York: Appleton.

Tönnies, Ferdinand. 1887. "Community and society." The urban sociology reader:13-22.

van Asselt, Marjolein, van 't Klooster, Susan, van Notten, Phillip and Smits, Livia. 2010. Foresight in Action: Developing Policy-oriented Scenarios, Earthscan, London.

van Notten, Philip, Jan Rotmans, Marjolein van Asselt, and Dale Rothman. 2003. "An updated scenario typology." Futures 35 (5):423-43.

Vanderstraeten, Raf. 2005. "System and environment: notes on the autopoiesis of modern society." Systems Research and Behavioral Science 22 (6):471-81. doi: 10.1002/sres.662. 
Annex

\begin{tabular}{|c|c|c|c|c|c|c|c|c|}
\hline $\mathbf{F}$ & $n$ & $\%$ & $n \exp$ & $\% \exp$ & Difference & \begin{tabular}{|l|} 
Difference $x 2$ \\
\end{tabular} & Chi2 & \\
\hline POL & 14953 & $20.2 \%$ & 8208.6 & $11.1 \%$ & 6744.4 & 45487530.9 & \begin{tabular}{|r|}
5541.478 \\
\end{tabular} & \\
\hline $\mathrm{ECO}$ & 11796 & $16.0 \%$ & 8208.6 & $11.1 \%$ & 3587.4 & 12869757.6 & 1567.847 & \\
\hline SCI & 12950 & $17.5 \%$ & 8208.6 & $11.1 \%$ & 4741.4 & 22481295.4 & 2738.764 & \\
\hline ART & 5911 & $8.0 \%$ & 8208.6 & $11.1 \%$ & -2297.6 & 5278761.5 & 643.080 & \\
\hline REL & 2382 & $3.2 \%$ & 8208.6 & $11.1 \%$ & -5826.6 & 33948749.6 & 4135.776 & \\
\hline LAW & 4210 & $5.7 \%$ & 8208.6 & $11.1 \%$ & -3998.6 & 15988446.5 & 1947.778 & \\
\hline HEA & 4546 & $6.2 \%$ & 8208.6 & $11.1 \%$ & -3662.6 & 13414313.2 & 1634.187 & \\
\hline EDU & 8821 & $11.9 \%$ & 8208.6 & $11.1 \%$ & 612.4 & 375088.2 & 45.695 & \\
\hline MED & 8308 & $11.2 \%$ & 8208.6 & $11.1 \%$ & 99.4 & 9889.2 & 1.205 & \\
\hline TOTAL & 73877 & $100.0 \%$ & 73877 & $100 \%$ & & & 18255.810 & \\
\hline F-Google & $\mathbf{n}$ & $\%$ & $n \exp$ & $\% \exp$ & Difference & $\begin{array}{l}\text { Difference } \mathrm{x} 2 \\
\end{array}$ & Chi2 & \\
\hline $\mathrm{POL}$ & 14953 & $20.2 \%$ & 15187.6 & $20.6 \%$ & -234.6 & 55053.0 & 3.625 & \\
\hline $\mathrm{ECO}$ & 11796 & $16.0 \%$ & 7631.5 & $10.3 \%$ & 4164.5 & 17343109.4 & 2272.571 & \\
\hline SCI & 12950 & $17.5 \%$ & 6756.1 & $9.1 \%$ & 6193.9 & 38364996.2 & 5678.612 & \\
\hline ART & 5911 & $8.0 \%$ & 4607.0 & $6.2 \%$ & 1304.0 & 1700495.0 & 369.114 & \\
\hline REL & 2382 & $3.2 \%$ & 9880.3 & $13.4 \%$ & -7498.3 & 56224652.6 & 5690.576 & \\
\hline LAW & 4210 & $5.7 \%$ & 11600.9 & $15.7 \%$ & $\begin{array}{l}-7390.9 \\
\end{array}$ & 54625481.3 & 4708.726 & \\
\hline HEA & 4546 & $6.2 \%$ & 4936.5 & $6.7 \%$ & -390.5 & 152459.9 & 30.884 & \\
\hline EDU & 8821 & $11.9 \%$ & 7440.9 & $10.1 \%$ & 1380.1 & 1904699.6 & 255.977 & \\
\hline MED & 8308 & $11.2 \%$ & 5836.3 & $7.9 \%$ & 2471.7 & 6109384.9 & 1046.794 & \\
\hline TOTAL & 73877 & $100.0 \%$ & 73877 & $100 \%$ & & & 20056.878 & \\
\hline F2000- & n2000- & $\%$ & n-1999 & n2000- $\exp$ & $\% \exp$ & Difference & \begin{tabular}{|l|} 
Difference $\mathrm{x}$ \\
\end{tabular} & Chi2 \\
\hline POL & 5139 & $19.7 \%$ & 9814 & 5370.4 & $20.56 \%$ & -231.4 & 53552.1 & 9.972 \\
\hline $\mathrm{ECO}$ & 3871 & $14.8 \%$ & 7925 & 4336.7 & $16.60 \%$ & -465.7 & 216890.8 & 50.013 \\
\hline$\overline{\mathrm{SCI}}$ & 4742 & $18.1 \%$ & 8208 & 4491.6 & $17.19 \%$ & 250.4 & 62710.9 & 13.962 \\
\hline ART & 2160 & $8.3 \%$ & 3751 & 2052.6 & $7.86 \%$ & 107.4 & 11530.3 & 5.617 \\
\hline REL & 904 & $3.5 \%$ & 1478 & 808.8 & $3.10 \%$ & 95.2 & 9064.8 & 11.208 \\
\hline LAW & 1771 & $6.8 \%$ & 2439 & 1334.7 & $5.11 \%$ & 436.3 & 190385.1 & 142.646 \\
\hline HEA & 1820 & $7.0 \%$ & 2726 & 1491.7 & $5.71 \%$ & 328.3 & 107767.3 & 72.244 \\
\hline EDU & 3250 & $12.4 \%$ & 5571 & 3048.6 & $11.67 \%$ & 201.4 & 40577.9 & 13.311 \\
\hline MED & 2470 & $9.5 \%$ & 5833 & 3191.9 & $12.22 \%$ & -721.9 & 521185.7 & 163.282 \\
\hline TOTAL & 26127 & $100.0 \%$ & 47745 & 26127 & $100.0 \%$ & & & 482.2538468 \\
\hline F vs All(x) & $\mathrm{n}$ & $\%$ & AlI & $F \exp$ & $\% \exp$ & Difference & Difference $\mathrm{x} 2$ & Chi2 \\
\hline POL & 14953 & $20.2 \%$ & 48161 & 13449.4 & $18.2 \%$ & $\begin{array}{r}1503.6 \\
\end{array}$ & 2260753.6 & 168.093 \\
\hline $\mathrm{ECO}$ & 11796 & $16.0 \%$ & 48361 & 13505.3 & $18.3 \%$ & -1709.3 & 2921609.6 & 216.331 \\
\hline SCI & 12950 & $17.5 \%$ & 44236 & 12353.3 & $16.7 \%$ & 596.7 & 356019.9 & 28.820 \\
\hline ART & 5911 & $8.0 \%$ & 21697 & 6059.1 & $8.2 \%$ & -148.1 & 21932.0 & 3.620 \\
\hline REL & 2382 & $3.2 \%$ & 4525 & 1263.6 & $1.7 \%$ & 1118.4 & 1250707.8 & 989.758 \\
\hline LAW & 4210 & $5.7 \%$ & 14115 & 3941.7 & $5.3 \%$ & 268.3 & 71958.8 & 18.256 \\
\hline HEA & 4546 & $6.2 \%$ & 14758 & 4121.3 & $5.6 \%$ & 424.7 & 180359.4 & 43.763 \\
\hline EDU & 8821 & $11.9 \%$ & 33011 & 9218.6 & $12.5 \%$ & -397.6 & 158115.5 & 17.152 \\
\hline MED & 8308 & $11.2 \%$ & 35682 & 9964.5 & $13.5 \%$ & -1656.5 & 2744123.7 & 275.389 \\
\hline TOTAL & 73877 & $100.0 \%$ & 264546 & 73877 & $100.0 \%$ & & & 1761.18076 \\
\hline
\end{tabular}

Table 4: Chi-square test of significant differences between observed and expected function system relevancies in Futures (own table).

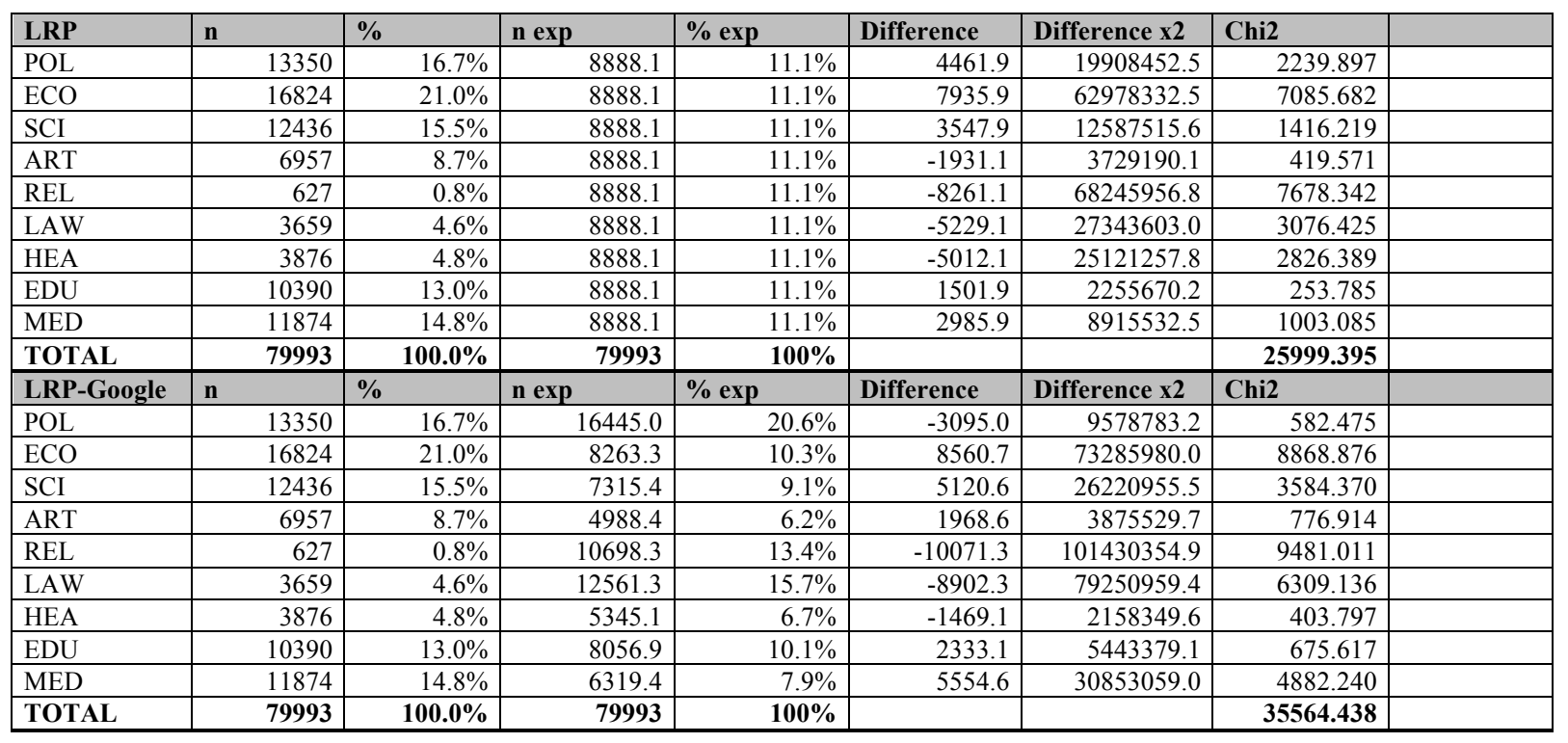




\begin{tabular}{|c|c|c|c|c|c|c|c|c|}
\hline LRP2000- & n2000- & $\%$ & n-1999 & n2000- exp & $\% \exp$ & \begin{tabular}{|l|} 
Difference \\
\end{tabular} & Difference $\mathrm{x} 2$ & Chi2 \\
\hline POL & 1552 & $13.7 \%$ & 11798 & 1939.4 & $17.2 \%$ & $\begin{array}{r}-387.4 \\
\end{array}$ & 150056.6 & 77.374 \\
\hline ECO & 2196 & $19.4 \%$ & 14628 & 2404.6 & $21.3 \%$ & -208.6 & 43501.7 & 18.091 \\
\hline SCI & 1856 & $16.4 \%$ & 10580 & 1739.2 & $15.4 \%$ & 116.8 & 13652.8 & 7.850 \\
\hline ART & 983 & $8.7 \%$ & 5974 & 982.0 & $8.7 \%$ & 1.0 & 1.0 & 0.001 \\
\hline REL & 112 & $1.0 \%$ & 515 & 84.7 & $0.7 \%$ & 27.3 & 747.7 & 8.832 \\
\hline LAW & 619 & $5.5 \%$ & 3040 & 499.7 & $4.4 \%$ & 119.3 & 14227.9 & 28.472 \\
\hline HEA & 547 & $4.8 \%$ & 3329 & 547.2 & $4.8 \%$ & -0.2 & 0.1 & 0.000 \\
\hline EDU & 1665 & $14.7 \%$ & 8725 & 1434.2 & $12.7 \%$ & 230.8 & 53256.0 & 37.132 \\
\hline MED & 1763 & $15.6 \%$ & 10111 & 1662.1 & $14.7 \%$ & 100.9 & 10188.9 & 6.130 \\
\hline TOTAL & 11293 & $100.0 \%$ & 68700 & 11293 & $100.0 \%$ & & & $\mathbf{1 8 3 . 8 8 2 4 2 1 4}$ \\
\hline LRP vs All(x) & n & $\%$ & All & LRP exp & $\% \exp$ & Difference & Difference $x 2$ & Chi2 \\
\hline POL & 13350 & $16.7 \%$ & 48161 & 14562.8 & $18.2 \%$ & $\begin{array}{r}-1212.8 \\
\end{array}$ & 1470997.4 & 101.010 \\
\hline $\mathrm{ECO}$ & 16824 & $21.0 \%$ & 48361 & 14623.3 & $18.3 \%$ & 2200.7 & 4842981.5 & 331.182 \\
\hline SCI & 12436 & $15.5 \%$ & 44236 & 13376.0 & $16.7 \%$ & -940.0 & 883621.7 & 66.060 \\
\hline ART & 6957 & $8.7 \%$ & 21697 & 6560.7 & $8.2 \%$ & 396.3 & 157050.2 & 23.938 \\
\hline REL & 627 & $0.8 \%$ & 4525 & 1368.3 & $1.7 \%$ & -741.3 & 549469.8 & 401.582 \\
\hline LAW & 3659 & $4.6 \%$ & 14115 & 4268.1 & $5.3 \%$ & -609.1 & 370967.9 & 86.917 \\
\hline HEA & 3876 & $4.8 \%$ & 14758 & 4462.5 & $5.6 \%$ & -586.5 & 343983.0 & 77.083 \\
\hline EDU & 10390 & $13.0 \%$ & 33011 & 9981.8 & $12.5 \%$ & 408.2 & 166615.9 & 16.692 \\
\hline MED & 11874 & $14.8 \%$ & 35682 & 10789.5 & $13.5 \%$ & 1084.5 & 1176212.7 & 109.015 \\
\hline TOTAL & 79993 & $100.0 \%$ & 264546 & 79993 & $100.0 \%$ & & & 1213.479575 \\
\hline
\end{tabular}

Table 5: Chi-square test of significant differences between observed and expected function system relevancies in Long Range Planning (own table). 


\begin{tabular}{|c|c|c|c|c|c|c|c|c|}
\hline TFSC & $\mathbf{n}$ & $\%$ & $n \exp$ & $\% \exp$ & Difference & Difference $\mathrm{x} 2$ & Chi2 & \\
\hline POL & 10541 & $18.2 \%$ & 6427.8 & $11.1 \%$ & 4113.2 & 16918597.0 & 2632.107 & \\
\hline ECO & 9345 & $16.2 \%$ & 6427.8 & $11.1 \%$ & 2917.2 & 8510185.5 & 1323.970 & \\
\hline SCI & 10358 & $17.9 \%$ & 6427.8 & $11.1 \%$ & 3930.2 & 15446646.7 & 2403.108 & \\
\hline ART & 4333 & $7.5 \%$ & 6427.8 & $11.1 \%$ & -2094.8 & 4388093.9 & 682.677 & \\
\hline REL & 758 & $1.3 \%$ & 6427.8 & $11.1 \%$ & -5669.8 & 32146380.0 & 5001.165 & \\
\hline LAW & 3671 & $6.3 \%$ & 6427.8 & $11.1 \%$ & -2756.8 & 7599823.7 & 1182.341 & \\
\hline HEA & 3592 & $6.2 \%$ & 6427.8 & $11.1 \%$ & -2835.8 & 8041635.6 & 1251.076 & \\
\hline EDU & 7086 & $12.2 \%$ & 6427.8 & $11.1 \%$ & 658.2 & 433256.5 & 67.404 & \\
\hline MED & 8166 & $14.1 \%$ & 6427.8 & $11.1 \%$ & 1738.2 & 3021416.5 & 470.056 & \\
\hline TOTAL & 57850 & $100.0 \%$ & $\mathbf{5 7 8 5 0}$ & $100 \%$ & & & 15013.904 & \\
\hline TFSC-Google & $\mathbf{n}$ & $\%$ & $n \exp$ & $\% \exp$ & Difference & Difference x2 & Chi2 & \\
\hline POL & 10541 & $18.2 \%$ & 11892.8 & $20.6 \%$ & -1351.8 & 1827371.4 & 153.654 & \\
\hline ECO & 9345 & $16.2 \%$ & 5975.9 & $10.3 \%$ & 3369.1 & 11350801.1 & 1899.428 & \\
\hline SCI & 10358 & $17.9 \%$ & 5290.4 & $9.1 \%$ & 5067.6 & 25680747.1 & 4854.233 & \\
\hline ART & 4333 & $7.5 \%$ & 3607.5 & $6.2 \%$ & 725.5 & 526312.5 & 145.893 & \\
\hline REL & 758 & $1.3 \%$ & 7736.9 & $13.4 \%$ & -6978.9 & 48704472.9 & 6295.122 & \\
\hline LAW & 3671 & $6.3 \%$ & 9084.2 & $15.7 \%$ & -5413.2 & 29302577.3 & 3225.669 & \\
\hline HEA & 3592 & $6.2 \%$ & 3865.5 & $6.7 \%$ & -273.5 & 74822.5 & 19.356 & \\
\hline EDU & 7086 & $12.2 \%$ & 5826.7 & $10.1 \%$ & 1259.3 & 1585957.4 & 272.190 & \\
\hline MED & 8166 & $14.1 \%$ & 4570.2 & $7.9 \%$ & 3595.9 & 12930137.2 & 2829.259 & \\
\hline TOTAL & $\mathbf{5 7 8 5 0}$ & $100.0 \%$ & $\mathbf{5 7 8 5 0}$ & $100 \%$ & & & 19694.804 & \\
\hline TFSC2000- & n2000- & $\%$ & n-1999 & n2000- exp & $\% \exp$ & Difference & Difference $\mathrm{x} 2$ & Chi2 \\
\hline POL & 5000 & $17.1 \%$ & 5541 & 5674.8 & $19.39 \%$ & -674.8 & 455321.3 & 80.236 \\
\hline ECO & 4911 & $16.8 \%$ & 4434 & 4541.0 & $15.51 \%$ & 370.0 & 136863.8 & 30.139 \\
\hline SCI & 5216 & $17.8 \%$ & 5142 & 5266.1 & $17.99 \%$ & -50.1 & 2514.2 & 0.477 \\
\hline ART & 2287 & $7.8 \%$ & 2046 & 2095.4 & $7.16 \%$ & 191.6 & 36712.1 & 17.520 \\
\hline REL & 254 & $0.9 \%$ & 504 & 516.2 & $1.76 \%$ & -262.2 & 68732.0 & 133.158 \\
\hline LAW & 1941 & $6.6 \%$ & 1730 & 1771.8 & $6.05 \%$ & 169.2 & 28639.8 & 16.165 \\
\hline HEA & 1810 & $6.2 \%$ & 1782 & 1825.0 & $6.24 \%$ & -15.0 & 225.7 & 0.124 \\
\hline EDU & 3830 & $13.1 \%$ & 3256 & 3334.6 & $11.39 \%$ & 495.4 & 245412.4 & 73.596 \\
\hline MED & 4021 & $13.7 \%$ & 4145 & 4245.1 & $14.50 \%$ & -224.1 & 50208.1 & 11.827 \\
\hline TOTAL & 29270 & $100.0 \%$ & 28580 & $\mathbf{2 9 2 7 0}$ & $100.0 \%$ & & & 363.2424698 \\
\hline TFSC ys All(x) & n & $\%$ & All & TFSC exp & $\% \exp$ & Difference & Difference $\mathrm{x} 2$ & Chi2 \\
\hline POL & 10541 & $18.2 \%$ & 48161 & 10531.7 & $18.2 \%$ & 9.3 & 86.9 & 0.008 \\
\hline ECO & 9345 & $16.2 \%$ & 48361 & 10575.4 & $18.3 \%$ & -1230.4 & 1513922.1 & 143.155 \\
\hline SCI & 10358 & $17.9 \%$ & 44236 & 9673.4 & $16.7 \%$ & 684.6 & 468711.7 & 48.454 \\
\hline ART & 4333 & $7.5 \%$ & 21697 & 4744.6 & $8.2 \%$ & -411.6 & 169434.8 & 35.711 \\
\hline REL & 758 & $1.3 \%$ & 4525 & 989.5 & $1.7 \%$ & -231.5 & 53597.5 & 54.166 \\
\hline LAW & 3671 & $6.3 \%$ & 14115 & 3086.6 & $5.3 \%$ & 584.4 & 341501.0 & 110.639 \\
\hline HEA & 3592 & $6.2 \%$ & 14758 & 3227.2 & $5.6 \%$ & 364.8 & 133058.5 & 41.230 \\
\hline EDU & 7086 & $12.2 \%$ & 33011 & 7218.7 & $12.5 \%$ & -132.7 & 17617.5 & 2.441 \\
\hline MED & 8166 & $14.1 \%$ & 35682 & \begin{tabular}{|l|}
7802.8 \\
\end{tabular} & $13.5 \%$ & 363.2 & 131902.8 & 16.905 \\
\hline
\end{tabular}

Table 6: Chi-square test of significant differences between observed and expected function system relevancies in Technological Forecasting and Social Change (own table). 


\begin{tabular}{|c|c|c|c|c|c|c|c|c|}
\hline All(x) & $\mathbf{n}(\mathbf{x})$ & $\%$ & $n \exp$ & $\% \exp$ & Difference & Difference $x 2$ & Chi2 & \\
\hline POL & 48161 & $18.2 \%$ & 29394.0 & $11.1 \%$ & 18767.0 & 352200289.0 & 11982.047 & \\
\hline ECO & 48361 & $18.3 \%$ & 29394.0 & $11.1 \%$ & 18967.0 & 359747089.0 & 12238.793 & \\
\hline SCI & 44236 & $16.7 \%$ & 29394.0 & $11.1 \%$ & 14842.0 & 220284964.0 & 7494.215 & \\
\hline ART & 21697 & $8.2 \%$ & 29394.0 & $11.1 \%$ & -7697.0 & 59243809.0 & 2015.507 & \\
\hline REL & 4525 & $1.7 \%$ & 29394.0 & $11.1 \%$ & -24869.0 & 618467161.0 & 21040.592 & \\
\hline LAW & 14115 & $5.3 \%$ & 29394.0 & $11.1 \%$ & -15279.0 & 233447841.0 & 7942.024 & \\
\hline HEA & 14758 & $5.6 \%$ & 29394.0 & $11.1 \%$ & -14636.0 & 214212496.0 & 7287.627 & \\
\hline EDU & 33011 & $12.5 \%$ & 29394.0 & $11.1 \%$ & 3617.0 & 13082689.0 & 445.080 & \\
\hline MED & 35682 & $13.5 \%$ & 29394.0 & $11.1 \%$ & 6288.0 & 39538944.0 & 1345.137 & \\
\hline TOTAL & 264546 & $100.0 \%$ & 264546 & $100 \%$ & & & 71791.021 & \\
\hline All-Google & $\mathbf{n}$ & $\%$ & $n \exp$ & $\% \exp$ & Difference & Difference $\mathrm{x} 2$ & Chi2 & \\
\hline POL & 48161 & $18.2 \%$ & 54385.4 & $20.6 \%$ & -6224.4 & 38742740.6 & 712.374 & \\
\hline ECO & 48361 & $18.3 \%$ & 27327.6 & $10.3 \%$ & 21033.4 & 442403839.8 & 16188.901 & \\
\hline SCI & 44236 & $16.7 \%$ & 24192.7 & $9.1 \%$ & 20043.3 & 401732604.1 & 16605.508 & \\
\hline ART & 21697 & $8.2 \%$ & 16497.1 & $6.2 \%$ & 5199.9 & 27039079.0 & 1639.021 & \\
\hline REL & 4525 & $1.7 \%$ & 35380.4 & $13.4 \%$ & -30855.4 & 952054600.8 & 26909.110 & \\
\hline LAW & 14115 & $5.3 \%$ & 41541.7 & $15.7 \%$ & -27426.7 & 752221589.9 & 18107.645 & \\
\hline HEA & 14758 & $5.6 \%$ & 17677.0 & $6.7 \%$ & -2919.0 & 8520349.2 & 482.003 & \\
\hline EDU & 33011 & $12.5 \%$ & 26645.1 & $10.1 \%$ & 6365.9 & 40525025.0 & 1520.920 & \\
\hline MED & 35682 & $13.5 \%$ & 20899.1 & $7.9 \%$ & 14782.9 & 218533127.2 & 10456.564 & \\
\hline TOTAL & 264546 & $100.0 \%$ & 264546 & $100 \%$ & & & 92622.046 & \\
\hline All2000- & n2000- & $\%$ & n-1999 & n2000- exp & $\% \exp$ & Difference & Difference $\mathrm{x} 2$ & Chi2 \\
\hline POL & 16006 & $17.2 \%$ & 28492 & 17422.1 & $18.67 \%$ & -1416.1 & 2005282.3 & 115.100 \\
\hline ECO & 15636 & $16.8 \%$ & 28532 & 17446.5 & $18.70 \%$ & -1810.5 & 3278050.9 & 187.891 \\
\hline SCI & 16377 & $17.6 \%$ & 25114 & 15356.5 & $16.46 \%$ & 1020.5 & 1041368.9 & 67.813 \\
\hline ART & 7697 & $8.3 \%$ & 12416 & 7592.0 & $8.14 \%$ & 105.0 & 11015.6 & 1.451 \\
\hline REL & 1809 & $1.9 \%$ & 2584 & 1580.0 & $1.69 \%$ & 229.0 & 52420.2 & 33.176 \\
\hline LAW & 5933 & $6.4 \%$ & 7551 & 4617.2 & $4.95 \%$ & 1315.8 & 1731249.9 & 374.954 \\
\hline HEA & 5702 & $6.1 \%$ & 8214 & 5022.6 & $5.38 \%$ & 679.4 & 461534.5 & 91.891 \\
\hline EDU & 12411 & $13.3 \%$ & 18496 & 11309.8 & $12.12 \%$ & 1101.2 & 1212643.9 & 107.221 \\
\hline MED & 11722 & $12.6 \%$ & 21172 & 12946.1 & $13.88 \%$ & -1224.1 & 1498420.4 & 115.743 \\
\hline TOTAL & 93293 & $100.0 \%$ & 152571 & 93293 & $100.0 \%$ & & & 1095.240075 \\
\hline
\end{tabular}

Table 7: Chi-square test of significant differences between observed and expected function system relevancies across Futures, Long Range Planning, and Technological Forecasting and Social Change (own table). 